\title{
Drivers of drought-induced shifts in the water balance through a Budyko approach
}

\author{
Tessa Maurer ${ }^{1,2}$, Francesco Avanzi ${ }^{3}$, Steven D. Glaser ${ }^{2}$, and Roger C. Bales ${ }^{2,4}$ \\ ${ }^{1}$ Blue Forest Conservation, Sacramento, CA, USA \\ ${ }^{2}$ Department of Civil and Environmental Engineering, University of California, Berkeley, CA 94720, USA \\ ${ }^{3}$ CIMA Research Foundation, via Armando Magliotto 2, 17100, Savona, Italy \\ ${ }^{4}$ Sierra Nevada Research Institute, University of California, Merced, CA, USA
}

Correspondence: Tessa Maurer (tmaurer@berkeley.edu)

\begin{abstract}
An inconsistent statistical relationship between precipitation and runoff has been observed between drought and nondrought periods, with less runoff usually observed during droughts than would be predicted using non-drought relationships. Most studies have examined these shifts using multi-linear regression models, which can identify correlations but are less appropriate for analyzing underlying hydrologic mechanisms. In this analysis, we show how the Budyko framework can be leveraged to quantify the impact of shifts in water allocation during drought using 30 years of data for 14 basins in California. We distinguish "regime" shifts, which result from changes in the aridity index along the same Budyko curve, from "partitioning shifts", which imply a change in the Budyko parameter $\omega$ and thus to the relationship among water-balance components that governs partitioning of available water. Regime shifts are primarily due to measurable climatic changes, making them predictable based on drought conditions. Partitioning shifts are related to nonlinear and indirect catchment feedbacks to drought conditions and are thus harder to predict a priori. We show that regime shifts dominate changes in absolute runoff during droughts, but that gains or losses due to partitioning shifts are still significant. We further discuss how basin characteristics and feedbacks correlate and may influence these shifts, finding that low aridity, high baseflow, a shift from snow to rain, and resilience of high-elevation runoff correlate to an increase in runoff as a fraction of precipitation during droughts. This new application of the Budyko framework can help identify mechanisms influencing catchment response to drought, with implications for water management in arid and drought-prone regions.
\end{abstract}

\section{Introduction}

Droughts can threaten human and natural systems worldwide, accounting for more than 50\% of all natural hazard deaths over the course of the 20th and early 21st century (Van Loon, 2015; Maskey and Trambauer, 2015). As baseline water stress intensifies globally due to growing populations and land-use changes (Hofste et al., 2019), the impact of meteorological and hydrologic droughts may become more severe (Masih et al., 2014). In Mediterranean climates with highly seasonal precipitation, droughts exacerbate already significant water-management challenges, as these basins typically rely on intricate systems of natural and built water storage to maintain water supply across regularly occurring seasonal and multi-year dry periods (He et al., 2017; Woodhouse et al., 2010). 
The need to adequately understand and predict the water-balance implications of droughts is becoming more acute as climate change makes basins susceptible to more severe and prolonged droughts (Dai, 2013; Trenberth et al., 2014; Woodhouse et al., 2010). Currently, it is understood that relationships between water balance components are not consistent between drought and non-drought periods. A particular focus is the change or shift in the precipitation-runoff relationship during droughts, which usually results in less observed runoff per unit of precipitation than would be predicted using non-drought relationships. These drought-induced shifts have been observed in basins around the world (e.g., Saft et al., 2016; Avanzi et al., 2020; Tian et al., 2020), compounding water shortages for municipal, industrial, and agricultural systems.

Despite documentation of these shifts and their implications for human water supply, it is not fully understood which hydrologic mechanisms trigger them nor whether these mechanisms are consistent across different droughts and basins (Bales et al., 2018). Most studies of drought-induced changes to the precipitation-runoff relationship have used statistical models to identify and analyze shifts. Saft et al. (2016) used multi-linear regression to identify factors associated with shifts during the decade-long Millennium Drought in Australia, finding that shifts are correlated to pre-drought catchment characteristics that make certain basins more susceptible to shifts, including aridity, rainfall seasonality, and interannual variability of groundwater storage. Potter et al. (2011) also looked at the Millennium Drought, using a regression approach to calculate the sensitivity of streamflow to anomalies in rainfall and maximum daily air temperature. These factors accounted for $73 \%$ of the reduction in streamflow, but left the remainder unexplained. Avanzi et al. (2020) followed the same statistical approach for California's Sierra Nevada, identifying shifts in the majority of basins in that mountain range and using a physically based model to identify interactions between evapotranspiration (ET) and subsurface water storage as the source of the shift. Examining a slightly wetter, monsoon region in China, Tian et al. (2020) developed a multivariate generalized additive model to identify basin characteristics, including climate characteristics, most associated with large negative shifts in the runoff coefficient (ratio of runoff to precipitation). They found that drier and lower catchments, based on the aridity index and mean catchment elevation, respectively, were more susceptible to large shifts.

During droughts, however, catchment feedbacks between ET and subsurface storage can introduce nonlinearities and/or hysteresis that are not fully accounted for by considering only the direct relationship between precipitation and runoff (Bales et al., 2018; Avanzi et al., 2020; Goulden and Bales, 2019). During wet periods when vegetation water demand is easily satisfied, ET becomes a more or less constant term, bounded by the energy availability (Bales et al., 2018; Budyko, 1974), and the relationship between precipitation and runoff appears linear. This can change during droughts through a number of vegetation- and water-balance-related mechanisms, which may trigger a hysteretic response in the water balance that appears to shift in the precipitation-runoff relationship (Avanzi et al., 2020). First, soil water storage can decouple ET from precipitation by allowing vegetation to withstand periods of mild to moderate drought. The extent to which soil storage acts to buffer the precipitation deficit depends on lithology and pre-drought water content of the soil as well as the vegetation type and rooting depth, which can vary significantly among and within basins (Bales et al., 2018; Oroza et al., 2018; Hahm et al., 2019b; Tague and Grant, 2009). For example, in the Sierra Nevada of California, deep regolith storage can support mixed conifer and evergreen needle-leaf species with deep rooting depths, but ET in grasslands and pine-oak forests is more responsive to yearly changes in precipitation (Bales et al., 2018; Klos et al., 2018). In areas like California with highly seasonal precipitation, dry- 
season baseflows can offer an approximation of the baseline soil water storage in a basin. Basin aridity may influence overall water available to support vegetation through dry periods (Avanzi et al., 2020; Saft et al., 2016; Tian et al., 2020). The second major factor is the vegetation feedback to reduced water availability. Even in areas with high soil water storage, prolonged and/or severe droughts can deplete subsurface storage, eliciting vegetation stress responses such as stomatal closure (Avanzi et al., 2020; Goulden and Bales, 2019) or, in extreme cases, tree die-offs (Bales et al., 2018). These changes to transpiration demand also influence water allocation between ET and runoff, even after the dry period is over. Finally, climate-induced changes other than precipitation deficit may contribute to shifts in the water balance. Changes in temperature may increase evaporative demand and thus increase ET in areas with sufficient water (Teuling et al., 2013; Mastrotheodoros et al., 2020). In basins with significant snowfall, temperature also influences precipitation phase and the elevation of the snow line (Zhang et al., 2017). These changes, in turn, influence the timing of available water (Rungee et al., 2019; Avanzi et al., 2020) and the spatial distribution of runoff production in the basin (Avanzi et al., 2020; Bales et al., 2018).

Here, we revisit the question of drought-induced shifts in the precipitation-runoff relationship through the lens of the Budyko framework in California's Sierra Nevada. The Budyko hypothesis (Budyko, 1974) is a conceptual water-balance model that has be used in numerous catchments around the world to characterize the long-term water balance as a trade-off between supply (precipitation) and demand (PET; e.g., Li et al., 2013; Zhang et al., 2008, 2001; Greve et al., 2016; Moussa and Lhomme, 2016; Shen et al., 2017; O'Grady et al., 2011; Gnann et al., 2019). As a conceptual model, the Budyko framework can provide a macroscale understanding of the relationship between water balance components across a catchment, while minimizing the need for high-resolution data or large parameter sets (Hrachowitz and Clark, 2017). The Budyko approach has been leveraged to examine the water-balance impacts of general climatic changes (Li et al., 2019; Wang and Alimohammadi, 2012), vegetation, (Zhang et al., 2016; Ning et al., 2019; Oudin et al., 2008), and land-use changes or other human activity (Liu et al., 2017; Shen et al., 2017), but its application to drought impacts specifically has been limited (see, e.g., Huang et al., 2017).

We apply the Budyko framework to the question of drought-induced shifts in the precipitation-runoff relationship for the first time, characterizing the water balance across three droughts in 14 basins in the Sierra Nevada. We distinguish "regime" shifts, which result from changes in the aridity index along the same Budyko curve, from "partitioning shifts", which imply a change in the Budyko calibration parameter and thus to the relationships between evaporative demand, precipitation, and ET that govern partitioning of available water. We use this new framing to answer the following questions: 1) Are changes to the precipitation-runoff relationship during droughts captured in the Budyko framework?; 2) What is the impact of these changes on partitioning of available water during drought?; and 3) Can any correlation be identified between partitioning shifts and known basin drought response mechanisms?

\section{Methods}

\subsection{Study area}

90 Our study area comprises the 14 major river basins draining into the Sacramento-San Joaquin Valley of California (Fig. 1). All basins in the study area have a Mediterranean climate, with seasonal precipitation that falls largely between October and 
https://doi.org/10.5194/hess-2021-55

Preprint. Discussion started: 29 March 2021

(c) Author(s) 2021. CC BY 4.0 License.
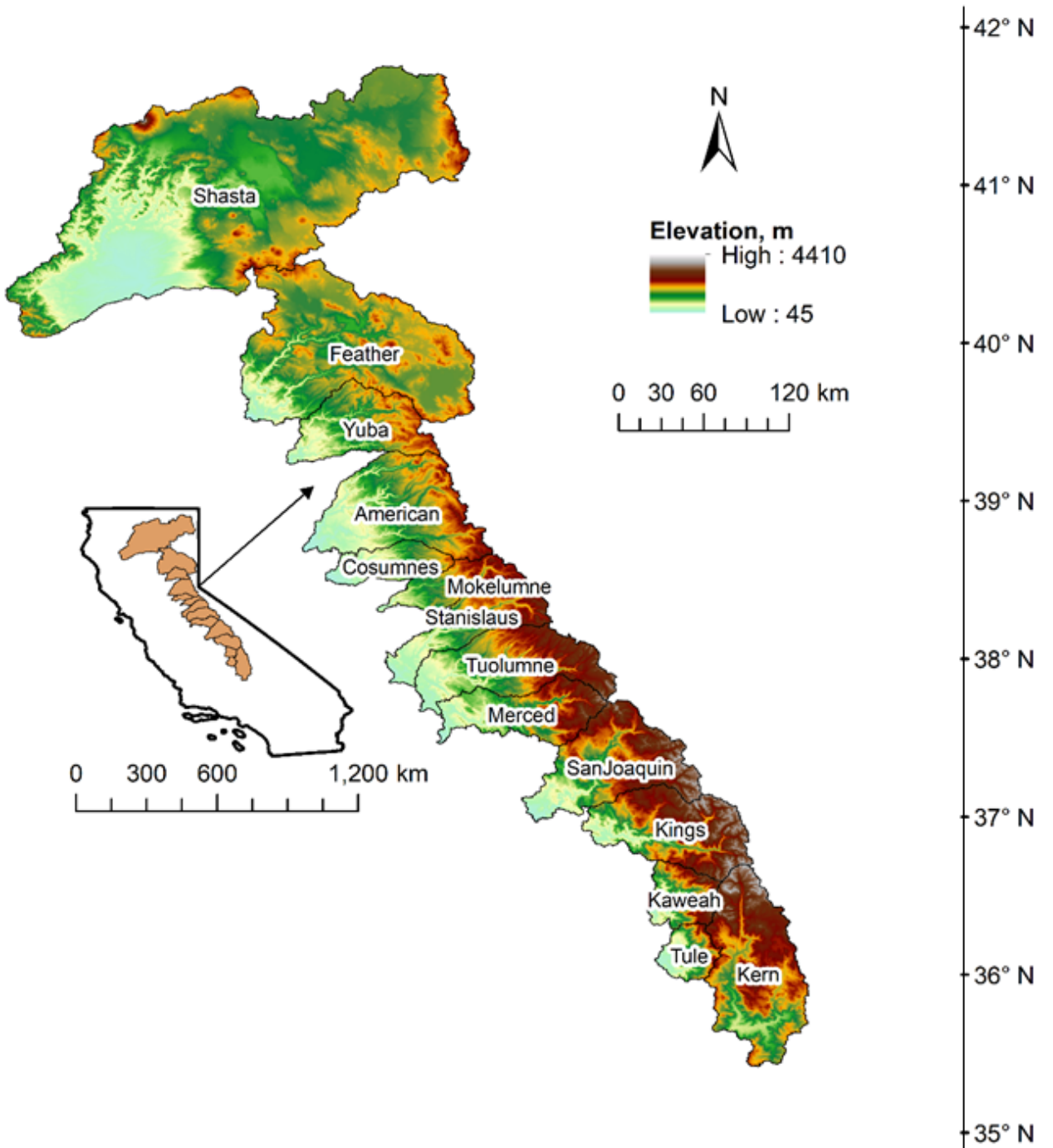

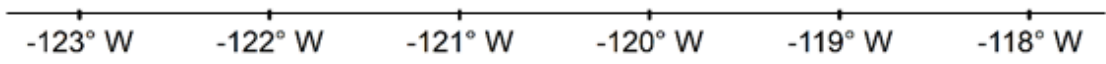

\section{Elevation, $\mathbf{m}$}

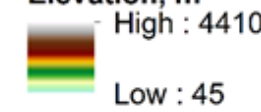

$0 \quad 30 \quad 60 \quad 120 \mathrm{~km}$
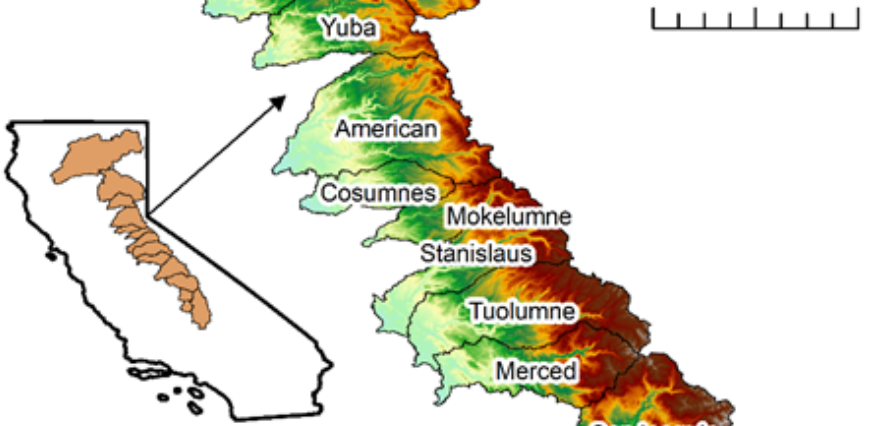

0300600

$1,200 \mathrm{~km}$

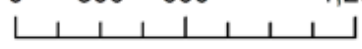

$+1$
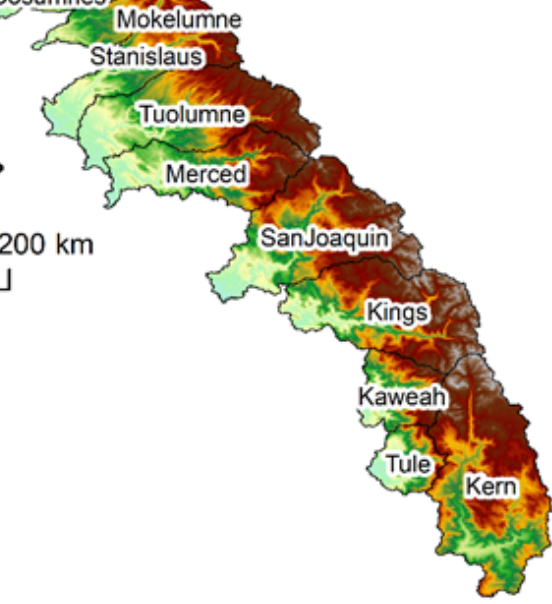

$-35^{\circ} \mathrm{N}$

Figure 1. Map of California, indicating extent of the river basins used in this study. The northern Sierra extends from the Shasta to Cosumnes, the central Sierra from the Mokelumne to the Merced, and the southern Sierra from the San Joaquin to the Kern. Elevation was derived from U.S. National Elevation Database Digital Elevation Models (EROS Data Center, 1999). 
May. The wet season is offset from the peak growing period, which occurs in the warmer summer months. Most basins have headwaters on the eastern edge, with elevations decreasing smoothly to the west. The exceptions are the Shasta, which has headwaters to the east, north, and far western edges and drains to the south; the Feather, the eastern two-thirds of which are lower and rain-shadowed; and the Kern, which has headwaters in the northern portion of the basin and drains to the south. Elevations generally increase from north to south in the Sierra Nevada, from an average elevation of $1530 \mathrm{~m}$ in the Feather to $2200 \mathrm{~m}$ in the Kern. Shasta has a high peak elevation (4300 m), but little surface area above $2400 \mathrm{~m}$. For ease of reference, we refer to all study basins collectively as the Sierra Nevada. The northern basins or northern Sierra Nevada includes the Shasta, Feather, Yuba, American, and Cosumnes basins; the central Sierra Nevada includes the Mokelumne, Stanislaus, Tuolumne, and Merced; and the southern Sierra Nevada includes the San Joaquin, Kings, Kaweah, Tule, and Kern.

\subsection{Data}

We used gridded data products of precipitation, temperature, and evapotranspiration to estimate water balance components for this study. Precipitation $(P)$ and minimum and maximum temperature on the daily timestep were obtained from the Parameterelevation Regressions on Independent Slopes Model (PRISM; Daly et al., 2008). Using the gridded temperature products, potential evapotranspiration (PET) was calculated with the Hamon method (Hamon, 1963) on a daily, pixel-by-pixel basis using mean daily PRISM temperatures. ET datasets were available on an annual (water year) basis, calculated for the Sierra Nevada following Roche et al. (2020). PRISM data have a pixel size of $800 \mathrm{~m}$ and were downscaled using a nearest-neighbor algorithm to match the $30 \mathrm{~m}$ pixel size of the ET data. Finally, runoff $(\mathrm{Q})$ was obtained in the form of monthly reconstructed unimpaired flow values at the outlet of each river basin from the California Data Exchange Center (http://cdec.water.ca.gov/index.html); see Supplement for the gauges used. Raster data were binned to two spatial scales we considered in this study: basin-wide and by $100 \mathrm{~m}$ elevation bands. All data were obtained for water years 1985-2018 and aggregated from their original timesteps to the annual (water year) timescale. (The water year in California runs from October first through September $30^{\text {th }}$ and is referred to by the latter of the two calendar years that it spans.) Finally, annual precipitation data were adjusted by the long-term average residual of $P-E T-Q$ so total basin storage over the period of record was zero.

\subsection{Extended Budyko framework}

The original Budyko formulation conceived of the water balance as a trade-off between supply, in the form of water from precipitation, and demand, in other words, potential evapotranspiration. Their mutual availability determines the partition of water between evapotranspiration and runoff. The aridity index, PET/P, is plotted against the fraction of precipitation that goes to ET (evaporative index). An aridity index less than one indicates an energy-limited area, where vegetation productivity is limited by potential evapotranspiration, while an aridity index greater than one indicates a water-limited area, where water availability is the limiting factor. This formulation was applied strictly to the long-term (i.e., 10+ years) water balance, a timescale over which change in storage could be assumed to average out to zero. To use the Budyko framework on a shorter timescale, we adopt the approach of (Du et al., 2016), who introduced an "extended" Budyko framework in which precipitation values are adjusted to include plant-accessible soil storage change, essentially expanding the available water supply $(\mathrm{P}-\Delta \mathrm{S}$; 
Fig. 2a). Annual soil storage is estimated using a second conceptual mass-conservation approach, the $a b c d$ model. The $a b c d$ model is an explicit water balance model developed by (Thomas, 1981) that provides estimates of direct and indirect runoff, soil water and groundwater storage, and actual ET, calibrated to streamflow at the basin outlet. This allowed for isolation of the change in plant-accessible soil water storage from deep subsurface storage changes. The abcd model assumes that "ET opportunity", the sum of actual ET over the timestep and soil water storage at the end of the timestep, is a function of available water. This relationship is parameterized by $a(0 \sim 1)$, representing the tendency for runoff to occur before soil is saturated, and $b$, the maximum ET opportunity. The rate that ET occurs from soil storage is assumed to be proportional to the ET opportunity, and thus soil storage is also a function of $b$. The remaining two parameters in the model, $c$ and $d$, control the partitioning of direct runoff from groundwater recharge and discharge. However, since we are interested only in change in soil storage, the last two parameters and related calculations were not used in this study. For full details of the extended Budyko model, see Du et al. (2016); more information on the abcd model, see Wang and Tang (2014). Results of the $a b c d$ calibration are presented in the Supplement. Note that using one year of model spin-up for the abcd model and calculating change in storage eliminates 2 years from the period of record.

Various mathematical models exist to represent data plotted in a Budyko framework; one of the most versatile is the $\mathrm{Fu}$ equation, in which the ET fraction of available water (evaporative index) is a function of the aridity index (PET/P) and the parameter $\omega$, a constant of integration (Fu, 1981; Zhang et al., 2004). The Fu model, modified for the extended Budyko framework following Du et al. (2016), is given in Eq. (1).

$\frac{E T}{P-\Delta S}=1+\frac{P E T}{P-\Delta S}-\left[1+\left(\frac{P E T}{P-\Delta S}\right)^{\omega}\right]^{1 / \omega}$

The value of $\omega$ will determine how close or far from the theoretical limit lines the data fall; the higher $\omega$, the closer the curve comes to the energy and water limit lines. Thus, for a given $\frac{P E T}{P-\Delta S}$ value, $\omega$ reflects the partitioning of available water between ET and runoff (Fig. 2a). The physical meaning of $\omega$ has been connected to various basin characteristics, including vegetation coverage type and density, average slope, and relative soil infiltration capacity (Zhang et al., 2001, 2016; Yang et al., 2007; Jaramillo et al., 2018) as well as climate characteristics such as the seasonal offset between peak precipitation and potential evapotranspiration (Ning et al., 2019). In the context of droughts, changes to the water balance can occur in one of two ways: 1) data can shift along the same curve, changing water balance components due to changes in the water or energy limitations and 2) data can shift to a new curve with a different omega value (Fig. 2b). We refer to the former as a regime shift, since the basin becomes more or less energy or water limited, and to the latter as a partitioning shift.

For each basin in our study area, we calibrated the Fu equation twice, once for drought years and another for non-drought years, allowing us to assess the changes due to one factor or the other and the implications for ET and runoff. The difference between the two $\omega$ values indicates the direction and intensity of the partitioning shift. In order to understand the effect of the two shift types on ET and runoff, we first calculated the hypothetical drought evaporative indices that would have been 
seen if only a regime shift had occured (no change in $\omega$; see "+" data points in Fig. 2b). This was by applying Eq. (1) to the annual observed drought values of $\frac{P E T}{P-\Delta S}$ and the non-drought $\omega$. We were then able to compare the hypothetical values to the non-drought values (black circles in Fig. 2b). These two sets of data points were converted to absolute values of ET and runoff based on annual precipitation and change in storage values; the difference between their averages was the impact due to a regime shift. To calculate the impact due to partitioning shifts, we subtracted the regime shift impacts from the total observed impacts.

\subsection{Identifying mechanisms of water balance shifts}

The shifts in the partitioning of available water can be related to feedback mechanisms between climatic conditions and catchment characteristics that either exacerbate or mitigate drought (Bales et al., 2018; Teuling et al., 2013; Avanzi et al., 2020). (In this study, "exacerbation" and "mitigation" are used with respect runoff). We examined four basin characteristics and responses to drought that may relate to observed shifts in the precipitation-runoff relationship. These are mechanisms that have previously been associated with drought-induced shifts in the water balance: 1) amount of available water storage (Avanzi et al., 2020; Rungee et al., 2019; Oroza et al., 2018; Hahm et al., 2019a); 2) timing of water availability, which is related to precipitation phase (Avanzi et al., 2020; Rungee et al., 2019; Berghuijs et al., 2014); 3) catchment aridity, which has been correlated with sensitivity to interannual changes in precipitation and departures from the historic mean precipitation (Berghuijs et al., 2014; Saft et al., 2016; Tian et al., 2020); and 4) high-elevation runoff, related to basin spatial heterogeneity that can serve to mitigate drought (Bales et al., 2018). Since not all of these mechanisms are directly measured across the Sierra, we use proxies to estimate their effects. Available soil water storage is estimated average dry-season flow (July-September) as a proxy. Due to the highly seasonal precipitation in the Sierra Nevada, flow during this period almost exclusively reflects outflow from storage rather than surface runoff. Changes to timing of water availability during drought was estimated by looking at changes to precipitation phase (rain versus snow; Avanzi et al., 2020; Rungee et al., 2019). Phase was estimated using a single-threshold temperature index method on a per-pixel basis. For each day, precipitation in pixels with an average temperature of $1{ }^{\circ} \mathrm{C}$ or above was assumed to be rain; otherwise it was assumed to be snow (Berghuijs et al., 2014). Catchment aridity $(P E T / P)$ was calculated directly, not including soil storage in order to isolate the effects of climate, and averaged over the study period. Finally, high-elevation runoff was estimated as the average annual precipitation minus ET for elevations above $2000 \mathrm{~m}$. This was compared to the area-normalized annual flow at the basin outlet to estimate the proportion of annual runoff from high elevations. 

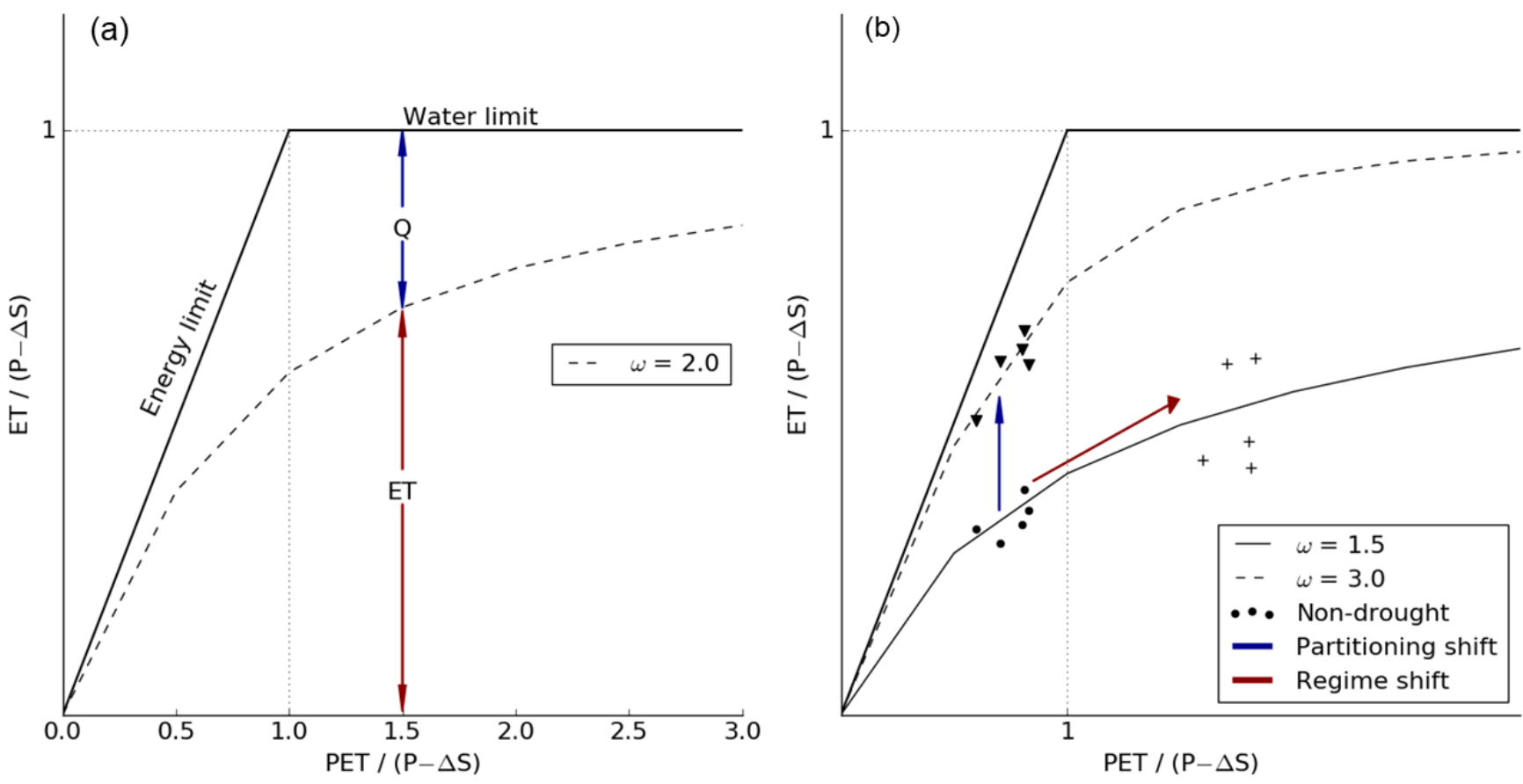

Figure 2. (a) Conceptual plot of extended Budyko framework, illustrating how the calibrated Fu equation dictates partitioning of available water and (b) conceptual illustration of drought-induced water balance shifts. ET is evapotranspiration, $\mathrm{P}$ is precipitation, $\Delta \mathrm{S}$ is change in plant-accessible soil storage, and Q is runoff.

\section{Results}

\subsection{Drought characterization}

The period of record of the available data covers three drought periods, as defined by the State of California (see https: //water.ca.gov/Water-Basics/Drought; accessed 29 July 2020): 1987-1992, 2007-2009, and 2012-2016. These droughts are referred to hereafter by the decade in which they ended (1990s, 2000s, and 2010s drought respectively). Average conditions varied across basins and droughts (Fig. 3). Average maximum daily temperature shows no significant change between droughts in the northern basins (average increase of $0.21^{\circ} \mathrm{C}$ ), but droughts in the central and southern Sierra basins are progressively warmer (average increases of 0.94 and $1.46{ }^{\circ} \mathrm{C}$, respectively). In contrast, average minimum daily temperature shows increases across all droughts and basins (increases of $1.62,1.88$, and $2.11^{\circ} \mathrm{C}$ for the northern, central, and southern basins respectively). Average precipitation during the droughts decreases from north to south across the Sierra Nevada, reflecting similar variability in long-term average conditions (average annual precipitation across the period of record was 1245, 1122, and $799 \mathrm{~mm}$ in the northern, central, and southern Sierra, respectively). In the northern Sierra, the earlier two droughts were the driest (1990s and 

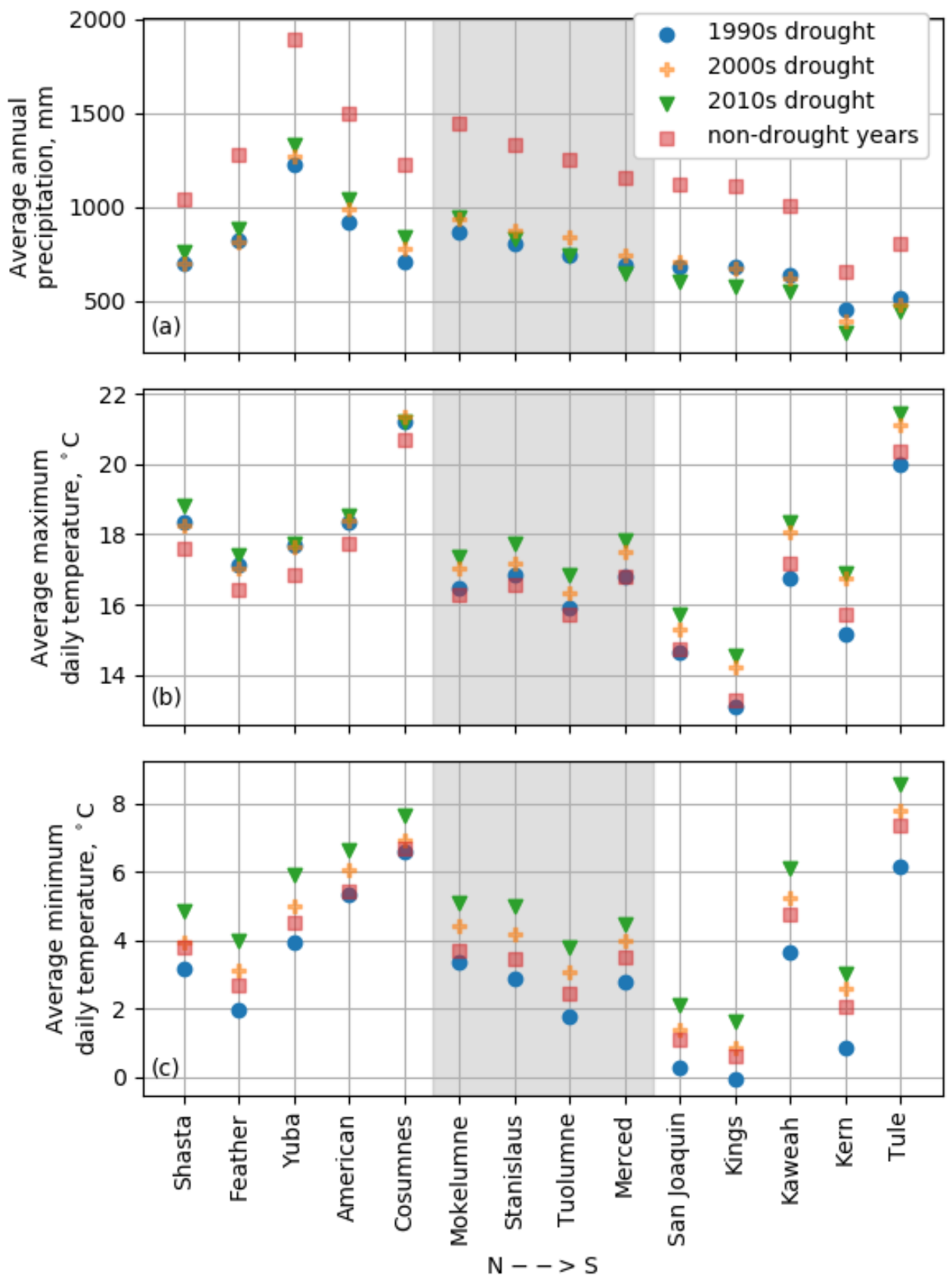

Figure 3. Climatic conditions during drought periods. The central Sierra is shaded in gray, with the northern and southern basins to the left and right, respectively. The most recent drought (2010s) was the wettest drought in the northern Sierra, but the driest in the southern Sierra (a). Maximum temperatures only increase in the central and southern Sierra (b), but minimum temperatures increase across the whole study area $(\mathrm{c})$. 
https://doi.org/10.5194/hess-2021-55

Hydrology and

Preprint. Discussion started: 29 March 2021

(c) Author(s) 2021. CC BY 4.0 License.

2000s), but but the 2010s drought was driest in the southern Sierra. Thus, droughts in the northern Sierra were progressively wetter with higher minimum temperatures, but droughts in the southern Sierra are progressively drier and hotter (Fig. 3).

\subsection{Water balance during droughts}

After calibration, the extended Budyko model showed high performance for simulating runoff in the study basins, with a maximum relative error on the order of $10^{-2} \mathrm{~mm}$ (see Supplement for details). We thus found it suitable for adjusting available water for the annual timestep. While a handful of years, amounting to $2.7 \%$ of all basin years, still lie above the water limit line, the model allowed for stable calibration in all basins of the Fu equation parameter $\omega$. Both drought and non-drought $\omega$ values are on the order of values reported in the literature ( 1 10; Zhang et al., 2004; Du et al., 2016; Li et al., 2013) for all basins except the Yuba, where extreme energy limitation resulted in very high $\omega$ values (Fig. 4). As the wettest basin in the Sierra Nevada (average annual precipitation of more than $1720 \mathrm{~mm}$ ), these conditions are consistent with basin climate. However, both $\omega$ values in the Yuba are far outside the normal range, to the point where they are effectively infinity (note that the two lines are indistinguishable in Fig. 4). As a result, we do not consider the direction or magnitude of the shift to carry significance and exclude the basin from further analysis. The changes along both Budyko axes (extended aridity index on the $\mathrm{x}$-axis and extended evaporative index on the $\mathrm{y}$-axis) between droughts and non-drought periods were significant in all basins to the $\alpha=0.01$ level $(p<0.01)$ based on a Kolmogorov-Smirnoff test, with the exception of change in the evaporative index on the Feather, which was significant to the $\alpha=0.05$ level ( $p=0.025$; see Supplement for full list of $p$-values).

In general, northern basins saw a shift in favor of runoff (decrease in $\omega$ ), while the southern basins saw a shift in favor of ET (increase in $\omega$ ), with the exception of the Cosumnes in the north and the San Joaquin and the Kings in the south (Fig. 4). Note that a shift in favor of ET or runoff does not guarantee that the quantity will increase in absolute terms. Likewise, movement to the right along the same Budyko curve will result in an increase in ET as a fraction of available water, but not necessarily in an increase in absolute ET, due to the drop in precipitation during droughts. The Tule and Kern basins in the south see a particularly strong shift in favor of ET (towards a higher $\omega$ value) while the Feather and Mokelumne further north see the opposite shift (partitioning changes in favor of runoff). In other words, drought may imply increases or decreases in the absolute quantities of ET and runoff.

The absolute changes in ET and runoff due to the partitioning shifts varied both in sign and magnitude, while regime changes were more consistent (Table 1 and Fig. 4). With respect to runoff, the magnitudes of regime-related changes dominate those of partitioning-related changes, with the former always at least 10 times higher than the latter (Table 1 and Fig. 5). This results in an overall drop in runoff across the study area, since runoff regime changes are always negative (Table 1). However, partitioning shifts still account for significant change in the southern Sierra, where regime-related changes are lower. In the case of ET, changes due to regime shifts still tend to be higher magnitude than partitioning shifts, but not exclusively. As a result, one type of shift can offset the other in basins where they have opposite signs. For example, ET is almost always reduced during droughts from regime shifts alone, but the Feather and Mokelumne would have seen an increase in overall ET if it were not for the curve shift downwards in favor of runoff (regime shift values are positive). 
https://doi.org/10.5194/hess-2021-55

Preprint. Discussion started: 29 March 2021

(c) Author(s) 2021. CC BY 4.0 License.

\section{(c) (i)}

Hydrology and

Earth System

Sciences

Discussions
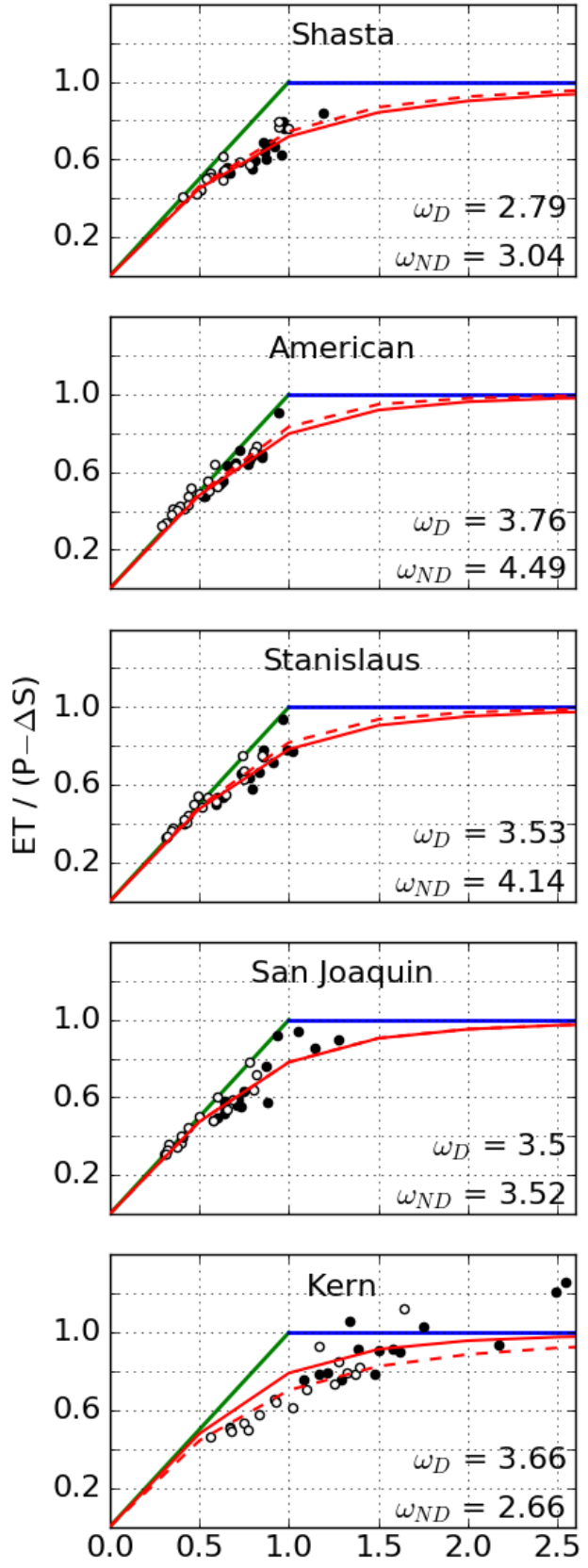
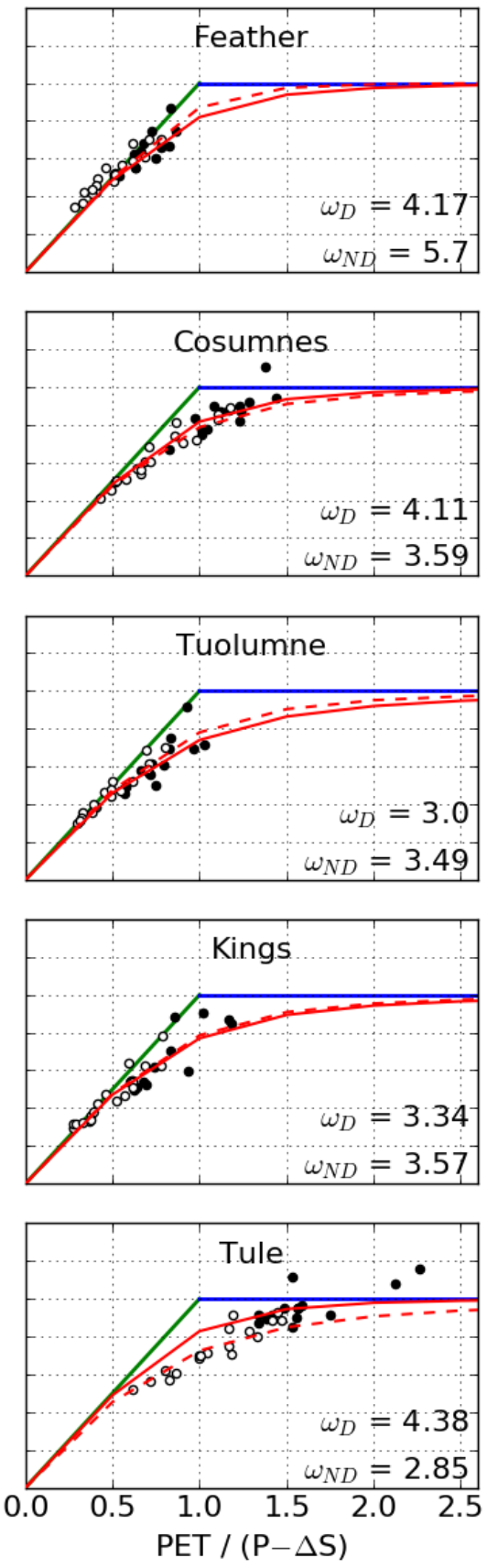
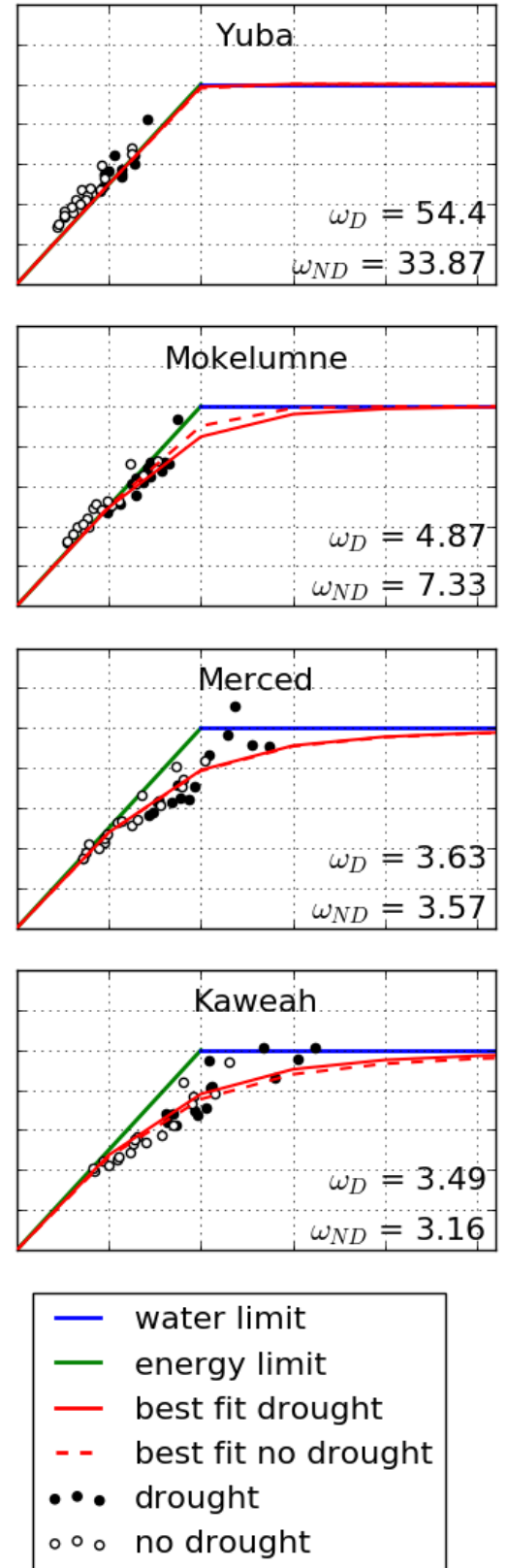

Figure 4. Annual (water year) water balances plotted in the extended Budyko framework, with calibrated best-fit lines for drought and non-drought periods. Values of $\omega$ are given for drought $(D)$ and non-drought $(N D)$ periods. 

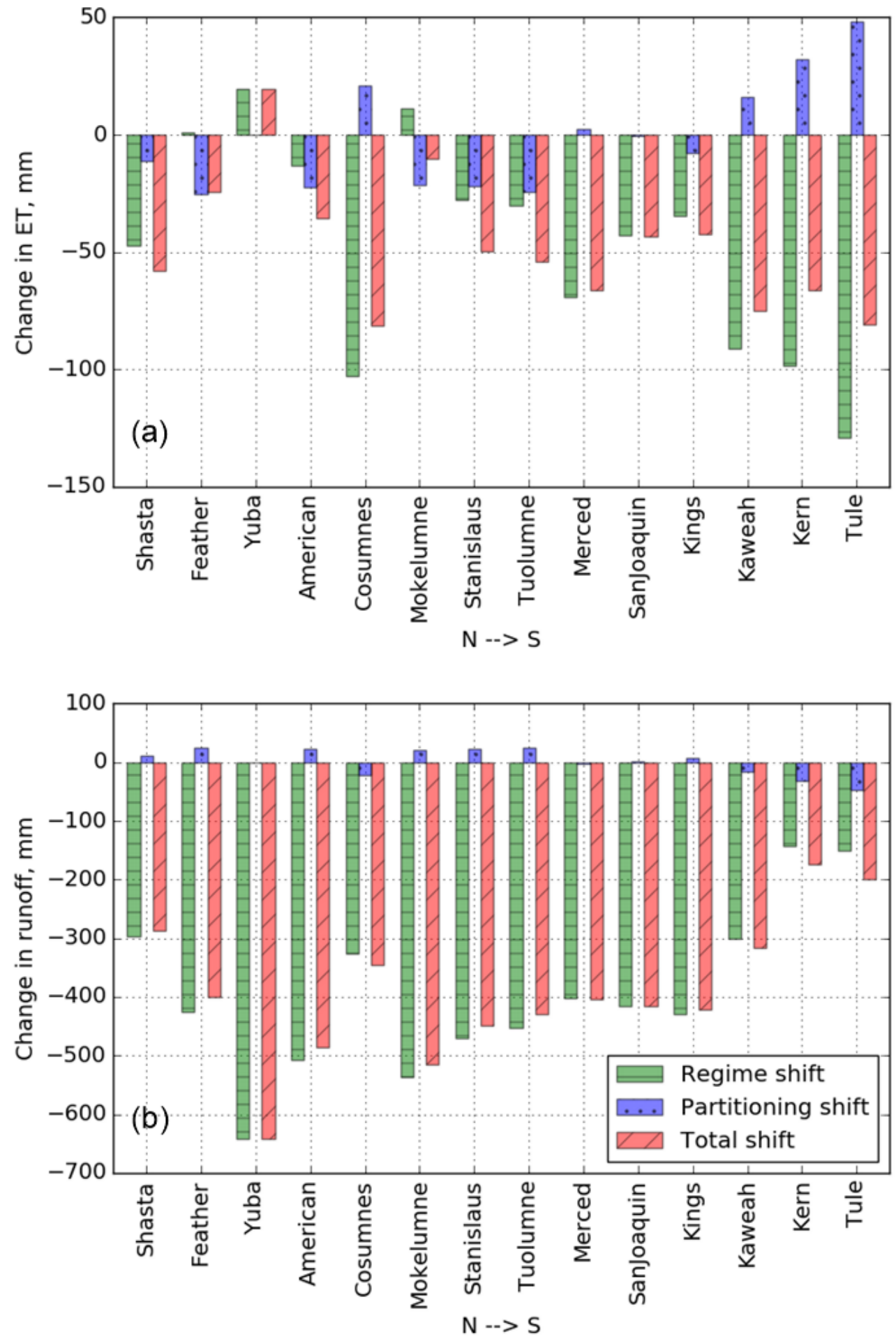

Figure 5. Fraction of changes in ET (a) and runoff (b) during droughts that can be attributed to regime vs partitioning shifts. 
https://doi.org/10.5194/hess-2021-55

Preprint. Discussion started: 29 March 2021

(c) Author(s) 2021. CC BY 4.0 License.

Table 1. Change in evapotranspiration and runoff during drought attributable to regime and partitioning shifts

\begin{tabular}{lcccccc}
\hline Basin & \multicolumn{3}{c}{ Evapotranspiration change, $\mathbf{m m}$} & \multicolumn{3}{c}{ Runoff change, $\mathbf{~ m m}$} \\
$(\mathrm{N} \rightarrow \mathrm{S})$ & Total $^{a}$ & Regime & Partitioning $^{b}$ & Total $^{a}$ & Regime $^{\text {Partitioning }}{ }^{b}$ \\
\hline Shasta & -58.1 & -47.1 & -11.1 & -287 & -298 & 11.1 \\
Feather & -24.2 & 1.0 & -25.2 & -400 & -425 & 25.2 \\
Yuba $^{c}$ & 19.5 & 19.5 & 0.0 & -642 & -642 & 0.0 \\
American & -35.5 & -13.1 & -22.5 & -485 & -507 & 22.5 \\
Cosumnes & -81.4 & -102.6 & 21.2 & -346 & -325 & -21.2 \\
Mokelumne & -10.4 & 11.1 & -21.5 & -515 & -537 & 21.5 \\
Stanislaus & -49.7 & -27.7 & -22.0 & -448 & -470 & 22.0 \\
Tuolumne & -54.3 & -30.0 & -24.2 & -429 & -453 & 24.2 \\
Merced & -66.5 & -69.0 & 2.5 & -405 & -402 & -2.5 \\
San Joaquin & -43.3 & -42.8 & -0.4 & -416 & -416 & 0.4 \\
Kings & -42.3 & -34.8 & -7.5 & -421 & -429 & 7.5 \\
Kaweah & -74.9 & -91.0 & 16.1 & -317 & -301 & -16.1 \\
Kern & -66.2 & -98.4 & 32.2 & -175 & -142 & -32.2 \\
Tule & -80.7 & -129.0 & 48.3 & -199 & -151 & -48.3 \\
\hline${ }^{a}$ Totals for each variable are the sum of Regime and Partitioning values. \\
${ }^{b}$ Partitioning values for evapotranspiration and runoff are the negative of each other. \\
${ }^{c}$ Since the $\omega$ values in Yuba are both effectively infinite, the partitioning shift has no effect.
\end{tabular}

\subsection{Drought feedback mechanisms}

\subsubsection{Catchment aridity}

Catchment aridity was higher in basins that saw a shift in favor of ET $(P E T / P \geq 0.766)$ and vice versa $(P E T / P \leq 0.749)$. Shift magnitude was highly correlated with average aridity $(r=0.83, p<0.001)$. The threshold dividing the two categories is notable, as $P E T / P=0.76$ has previously been identified as the cutoff between energy-limited water balance regimes and drier regimes, equitant and water-limited (McVicar et al., 2012). Thus, basins where more water than energy is available for evapotranspiration see a shift towards runoff, while those where water and energy availability are more or less equal or where energy is more plentiful see a shift towards ET.

\subsubsection{Dry-season baseflow}

Baseflow was generally higher in basins that saw a partitioning shift in favor of runoff, with an average baseflow of $14.5 \mathrm{~mm}$ in those basins versus $6.9 \mathrm{~mm}$ in those that shifted in favor of ET (Fig. 6). The only basin that showed a significant departure from other basins displaying similar partitioning behavior was the American, which had relatively low baseflow. Notably, the basins where shifts were the opposite of what would be expected geographically (the Cosumnes shifting towards ET versus the San Joaquin and Kings further south shifting toward runoff) showed the most extreme baseflow values. The Cosumnes had the lowest flows at $2.12 \mathrm{~mm}$ and the San Joaquin and Kings had the highest, at 20.9 and $21.9 \mathrm{~mm}$, respectively. 


\subsubsection{Precipitation phase}

Percent of precipitation falling as snow decreased during drought in all basins except Tule. northern Sierra Nevada basins saw greater percent decreases than the central and southern Sierra $(-2.3 \%,-1.95 \%$, and $-0.52 \%$, respectively), despite the latter having seen greater temperature increases. The northern basins are overall lower elevation, so more area lies in the rain-snow transition where precipitation phase is susceptible to increases in temperature. For the most part, basins that saw a decrease in $\omega$ (shift towards runoff) saw a stronger decrease in percent snow. The Pearson correlation coefficient of $r=0.62(p<0.05)$ between change in $\omega$ and percent change in snow shows a moderate relationship between the two.

\subsubsection{Precipitation excess above $2000 \mathrm{~m}$}

Using P-ET above $2000 \mathrm{~m}$ as an index for high-elevation runoff and expanding the analysis to the rest of the study site, we find that most basins in the Sierra rely substantially on high-elevation runoff. Nine of the 13 basins analyzed (excluding the Yuba) saw an average high-elevation runoff fraction above 0.33 (those that did not were the Shasta, Feather, American, and Cosumnes). However, overall fraction of runoff from high elevations was not significantly correlated with changes in $\omega$. Instead, we found that changes in high-elevation runoff between drought and non-drought periods was moderately negatively correlated with partitioning shift $(r=-0.55, p<0.05)$. In other words, strong decreases in high-elevation runoff during drought were associated with strong shifts in favor of ET and vice versa. Specifically, basins that see a significant decrease ( $>9 \%)$ in highelevation runoff during drought see strong shift towards ET (Tule, Kaweah, Kern). All other basins, including the Cosumnes and Merced, which shifted in favor of ET, saw a positive or small negative percent changes in high-elevation runoff (Fig. 6).

\section{Discussion}

The Budyko approach used here has allowed us to distinguish two types of drought-induced shifts, regime and partitioning, for the first time. To fully explore how this new framework can be leveraged to better understand drought implications for the water balance, we present the discussion in three sections. We begin with an explanation of how regime and partitioning shifts primarily relate to climate and basin feedbacks, respectively (Sect. 4.1). Next, we discuss the relative impact of these shifts on absolute values of ET and runoff in the Sierra Nevada during drought (Sect. 4.2). Finally, we offer an interpretation of how partitioning shifts may relate to hydrologic processes by analyzing correlations between shifts and the four basin drought responses enumerated in Sect. 3.3 (Sect. 4.3).

\subsection{Interpreting regime and partitioning shifts}

Due to the nonlinear relationship between the aridity and evaporative indices in the Budyko framework (Fig. 2), both regime and partitioning shifts result in changes in the precipitation-runoff relationship as observed in other studies (e.g., Avanzi et al., 2020; Tian et al., 2020; Saft et al., 2016; Petheram et al., 2011). The primary difference, however, is that regime shifts movement along the same Budyko curve (Fig. 2b) - are reflective of predictable climatic variability during drought, while 
partitioning shifts represent a change to a new equilibrium state that cannot be easily forecast a priori. Regime shifts are almost exclusively controlled by measurable climatic factors through PET (a function of temperature) and precipitation. Endogenous basin characteristics (i.e., factors influencing available subsurface water storage) are a secondary influence, since even during drought withdrawals from the subsurface were 10 times less than precipitation rates. Thus, readily available observations of climate patterns are mostly sufficient to predict regime shifts and their impact on water resources during drought. Partitioning shifts, on the other hand, are a function of nonlinear and indirect catchment feedbacks to climatic changes during drought. While there is understanding that these mechanisms relate at least in part to vegetation and subsurface water storage interactions (Avanzi et al., 2020), a relative dearth of data related to both has so far prevented a full enumeration of these mechanisms and how they interact. This makes the impact of partitioning shifts on drought water supply largely unpredictable and highlights the need for future research focused on process understanding of these shifts.

The ability to distinguish these types of shifts while allowing for each to induce nonlinear changes in the water balance is an advantage of the Budyko framework. Previous studies have used linear models to relate precipitation, Box-Cox transformed runoff, and a dummy variable to account for drought (Saft et al., 2016; Avanzi et al., 2020). This statistical framing is primarily concerned with the direct impact of precipitation on runoff. The Budyko framework, however, considers allocation of water relative to the aridity index, a combination of two major water-balance drivers (PET and precipitation), rather than precipitation alone. Moreover, the Budyko framework governs available water partitioning by physical behavior under limit conditions (when the aridity index is zero, all water goes to runoff; when the aridity index is one, all water goes to ET). This framework allows for the possibility that even expected and predictable water balance changes during drought may be nonlinear and that some shifts observed in other studies may be the result of factors that are not captured in a 2-dimensional precipitation-runoff plane. This critical difference may explain that though previous studies have observed less runoff than expected without a shift in relationship (Avanzi et al., 2020; Tian et al., 2020; Saft et al., 2016), most study basins under the Budyko framework show a shift towards more runoff as a fraction of available water than would be expected using non-drought relationships (decrease in $\omega$; Fig. 4). The direct precipitation-runoff relationship and the Budyko framework are complementary approaches, but the understanding that water balance shifts during droughts are due to many interacting factors (see Avanzi et al. (2020) and Saft et al. (2016)) argues for expanding the tools used to analyze this phenomenon. These and new approaches should be the subject of further study.

\subsection{Impact of regime and partitioning shifts}

Nonlinearities in the relationship between the aridity index, $\omega$, and the evaporative index also mean that regime and partitioning shifts are not equally responsible for changes in ET and runoff during drought (Fig. 5 and Table 1). Regime shifts accounted for at least $75 \%$ of runoff reductions across the study area and also dominated changes in absolute ET in most basins. This suggests that most reductions in runoff during drought may be predictable from precipitation and other climate factors that are not considered by a precipitation-runoff relationship; however, the relatively small impacts due to partitioning shifts still represent significant volumes of water. For example, partitioning shifts in the Feather River provide $25.2 \mathrm{~mm}$ of additional runoff annually during droughts (4.6\% of average annual runoff). Over the approximately $9400 \mathrm{~km}^{2}$ basin, this amounts to 
more than 225 million $\mathrm{m}^{3}$ of water. In the Kern, with an area of approximately $5300 \mathrm{~km}^{2}$, a loss of $32.2 \mathrm{~mm} \mathrm{yr}^{-1}(22 \%$ of average annual runoff) due to partitioning shifts translates into nearly 290 million $\mathrm{m}^{3}$.

It is important to note that movement in the Budyko space due to regime shifts do not necessarily indicate whether absolute values of ET and runoff will increase or decrease. Since the aridity index $(P E T / P-\Delta S)$ typically increases during droughts, regime shifts result exclusively in an increase in ET as a fraction of precipitation. This results in a decrease to absolute runoff across all basins in the study area, but usually does not translate into an increase in absolute ET (Table 1) due to the available water decreasing significantly during drought. Only in the Feather and Mokelumne basins did ET increase (1 and $11.1 \mathrm{~mm}$ respectively), indicating that available water was sufficient to support vegetation. Other than the Yuba, the Feather and Mokelumne basins are the wettest in the Sierra Nevada (average annual precipitation of 1180 and $1290 \mathrm{~mm}$, respectively), while the water availability in the Feather may also be partly supported by the greater groundwater storage in parts of the basin (Avanzi et al., 2020). An increase in ET during droughts has also been observed or predicted in the overall wetter and colder European Alps (Teuling et al., 2013; Mastrotheodoros et al., 2020).

The direction of a partitioning shift, on the other hand, is a direct indicator of the sign of the change in absolute ET or runoff. This is because the partitioning shift relates to change in evaporative index for a given aridity index; in other words, assuming a constant amount of available water. Furthermore, because the derivative of the evaporative index with respect to $\omega$ is nonlinear (see Eq. (1)), the same unit change starting on the higher end of the $\omega$ spectrum will have less impact on the evaporative index than changes on the lower end (Fig. 5). For example, the Feather and Tule see the same magnitude shift in $\omega(|\omega|=1.52$ ) but in different directions and starting from different non-drought values ( $\omega_{N D}=5.7$ and 2.85, respectively). In the wetter Feather, the increase in runoff due to partitioning is $25.2 \mathrm{~mm}$, but in the more southern Tule, the decrease in runoff is nearly twice as large at $48.3 \mathrm{~mm}$ (Table 1). This is further demonstrated in the Kern and Tule, which had the lowest non-drought omega values (2.66 and 2.85, respectively) and where runoff was most impacted. This shows that even basins within the same mountain range or region may have high variability in their vulnerability to drought. It further suggests that water agencies that rely on multiple headwater basins (not uncommon in areas like California with highly interconnected water systems), should consider their management strategies on a per-catchment basis.

\subsection{Mechanisms of partitioning shifts during drought}

In this section, we discuss how the relationships observed between the change in $\omega$ and four basin response mechanisms (see

Sect. 3.3) may inform our understanding of processes that drive partitioning shifts. Such processes are related to endogenous basin characteristics that dictate the response of the catchment's water balance to drought climate conditions (Troch et al., 2015). Under the Budyko framework, these responses primarily impact the water balance through partitioning shifts, and their effects are captured by the $\omega$ parameter, which controls the distribution of available water between ET and runoff. Previous literature has related $\omega$ or similar Budyko parameters to basin characteristics including vegetation type (Zhang et al., 2001; Ning et al., 2017, 2019, 2020; Roderick and Farquhar, 2011), topographic features like average slope (Yang et al., 2007, 2009; Ning et al., 2019), and soil characteristics like infiltration capacity and soil water storage (Ning et al., 2019; Yang et al., 2007). 

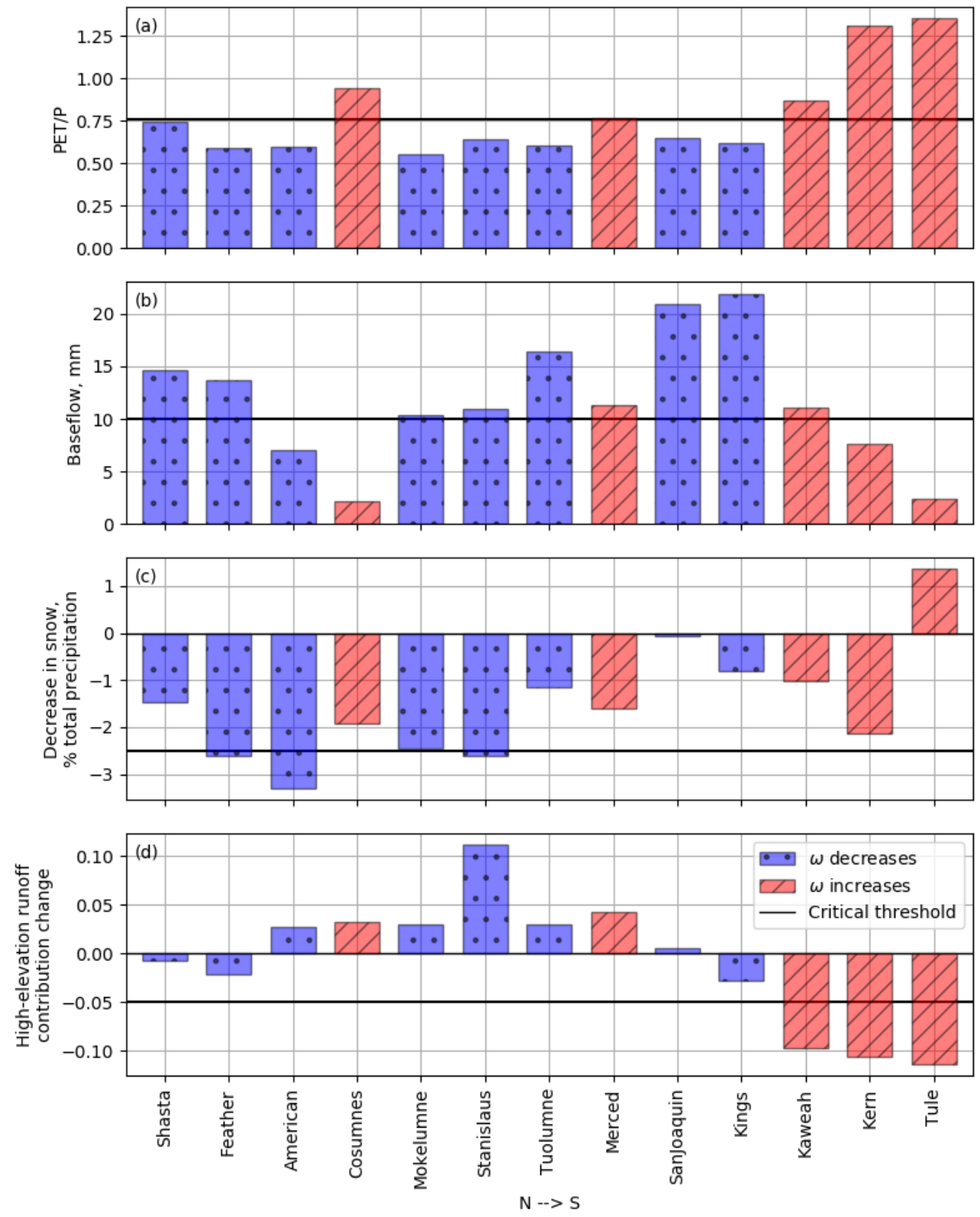

Figure 6. Basin responses driving partitioning shifts. Increases in $\omega$ reflect a shift in favor of ET; decreases reflect a shift in favor of runoff. 
Table 2. Summary of basin response mechanisms influencing water partitioning relative to stated threshold

\begin{tabular}{|c|c|c|c|c|}
\hline $\begin{array}{l}\operatorname{Basin}^{a} \\
(\mathrm{~N} \rightarrow \mathrm{S})\end{array}$ & $\begin{array}{l}\text { Average } \\
\text { aridity }^{b}\end{array}$ & $\begin{array}{l}\text { Average } \\
\text { baseflow }\end{array}$ & $\begin{array}{c}\text { Decrease in } \\
\text { snow }\end{array}$ & $\begin{array}{l}\text { High-elevation runoff } \\
\text { fraction change }\end{array}$ \\
\hline Threshold: & 0.76 & $10 \mathrm{~mm}$ & $-2.5 \%$ & -0.1 \\
\hline Shasta (Q) & $-(\mathrm{Q})$ & $+(\mathrm{Q})$ & + & + \\
\hline Feather $(Q)$ & - (Q) & $+(\mathrm{Q})$ & $-(\mathrm{Q})$ & + \\
\hline American (Q) & $-(\mathrm{Q})$ & $-(\mathrm{ET})$ & $-(\mathrm{Q})$ & + \\
\hline Cosumnes (ET) & $+(\mathrm{ET})$ & $-(\mathrm{ET})$ & + & + \\
\hline Mokelumne (Q) & $-(\mathrm{Q})$ & $+(\mathrm{Q})$ & $-(\mathrm{Q})$ & + \\
\hline Stanislaus (Q) & - (Q) & $+(\mathrm{Q})$ & $-(\mathrm{Q})$ & + \\
\hline Tuolumne (Q) & - (Q) & $+(\mathrm{Q})$ & + & + \\
\hline Merced (ET) & $+(\mathrm{ET})$ & $+(\mathrm{Q})$ & + & + \\
\hline San Joaquin (Q) & $-(\mathrm{Q})$ & $+(\mathrm{Q})$ & + & + \\
\hline Kings (Q) & $-(\mathrm{Q})$ & $+(\mathrm{Q})$ & + & + \\
\hline Kaweah (ET) & $+(\mathrm{ET})$ & $+(\mathrm{Q})$ & + & $-(\mathrm{ET})$ \\
\hline Kern $(\mathrm{ET})$ & $+(\mathrm{ET})$ & $-(\mathrm{ET})$ & $-(\mathrm{Q})$ & $-(\mathrm{ET})$ \\
\hline Tule (ET) & $+(\mathrm{ET})$ & $-(\mathrm{ET})$ & + & $-(\mathrm{ET})$ \\
\hline
\end{tabular}

Since the four mechanisms we examine are all fundamentally related to these basin features, our work is broadly consistent with previous literature on the interpretation of this parameter.

Regarding the first metric, aridity, there is a clear pattern in partitioning shifts where the wet catchments see a shift in favor of runoff while the arid basins shift in favor of ET. This reflects both the greater average aridity of the southern basins as well as the more severe drought conditions (higher temperatures and lower precipitation; Goulden and Bales, 2019). As a lowerelevation basin, the Cosumnes is also more arid and sees a shift toward ET. The high correlation between average PET and shift in $\omega$ suggests that overall climate may predispose basins to a certain drought response through long-term co-evolution of landscapes and climate (Troch et al., 2015). This agrees with previous findings that catchment aridity is a key predictor of shifts in the runoff coefficient (Saft et al., 2016; Tian et al., 2020). Aridity is both a key indicator of catchment climate (Budyko, 1974) as well as being correlated with vegetation and water storage (Saft et al., 2016), both of which also influence the intensity of the feedback cycle between precipitation deficit and vegetation response. Our findings again suggest that dry basins are likely to become drier and that this impact is likely to have a disproportionate impact on runoff compared to wetter basins (Sect. 4.2).

The second metric, amount of dry-season baseflow, provides an estimate of the baseline amount of subsurface storage in a catchment, thus serving as a proxy for a basin's potential for buffering the precipitation deficit with soil storage. Higher baseflows were associated with shifts in favor of runoff, reflecting one or more basin mechanisms supporting streamflow during drought. They may relate to deep groundwater contributions to streams, which are less vulnerable to plant water use, particularly on shorter timeframes, and can thus sustain flows during periods when vegetation is more heavily reliant on near- 
surface storage. If baseflows are indicative of higher groundwater tables, these soils may become saturated more quickly during a rainfall event, thus leading to saturation-excess runoff (Petheram et al., 2011). The more and higher groundwater tables would make a basin less susceptible to losing this mechanism over large areas during drought (Saft et al., 2016). Finally, areas with higher average baseflow levels are less likely to see storage severely depleted by vegetation over the course of a multi-year drought and are able to continue sustaining streamflow (Rungee et al., 2019). The fact that geographically anomalous basins (Cosumnes, San Joaquin, and Kings) showed the most extreme baseflows suggests that subsurface storage can be a significant factor in basin response, both mitigating and exacerbating drought conditions.

Third, higher temperatures during droughts may induce a shift in precipitation phase from rain to snow, changing the timing of water availability to earlier in the season. Other analyses of the Sierra Nevada water balance during droughts (e.g. Rungee et al., 2019) suggest that snowpack augments plant-accessible subsurface storage by 1) increasing infiltration efficiency, as snowmelt is slow as compared to intense rainfall events, and 2) shortening the length of the dry season by delaying infiltration. As was suggested by Avanzi et al. (2020) and Shao et al. (2012), this implies that shifts from snow to rain may favor runoff rather than ET, at least on the seasonal timescale, since more water is able to runoff or infiltrate to deep groundwater in periods of low vegetation productivity. Our findings are consistent with this hypothesis: larger changes in percentage of precipitation that fell as snow (>2.5\%) mostly overlap with basins that shift in favor of runoff during droughts (the only exception being the low-elevation Cosumnes basin). Basins where there was little change to snow percentage did not necessarily see a shift in favor of ET, but loss of SWE may be a predictor of greater runoff.

Finally, the generation of high-elevation runoff, which is more resilient to increases in PET due to overall lower temperatures and sparser vegetation, can help mitigate runoff losses elsewhere in the basin (Goulden and Bales, 2019). Given the orographic effect of the Sierra Nevada, high elevations may also be less susceptible to decreases in precipitation. Our findings on the importance of high-elevation runoff broadly agree with Goulden and Bales (2019), who identified high-elevation runoff as a drought mitigation factor in the Kings River during the 2012-2016 drought. Here, we find that resilient high-elevation runoff is not guaranteed to mitigate drought so much as decreases in high-elevation runoff act to exacerbate drought. Both the Merced and Cosumnes basins saw slight increases in high-elevation-runoff fraction during drought, but saw a shift in favor of ET. However, all basins that saw a strong decrease in fractional contribution of high-elevation runoff $(>0.5)$ also saw a shift in favor of ET (Kaweah, Kern, Tule). Thus, high-elevation runoff may not always offset other factors like high aridity and low baseflow, but loss of this important runoff source may shift water allocation towards ET. Alternatively, loss of high-elevation runoff may be correlated with other changes that cause a shift towards ET, such as temperature increases driving increases in ET demand at high elevations or lateral redistribution of precipitation excess from higher elevations to unsaturated soil at lower elevations.

\section{Conclusions}

Applying the Budyko framework to assess the impact of droughts on the water balance, we identify two distinct types of shifts in the water balance during droughts, regime and partitioning shifts. We show how regime shifts are primarily due to predictable 
https://doi.org/10.5194/hess-2021-55

Preprint. Discussion started: 29 March 2021

(c) Author(s) 2021. CC BY 4.0 License.

climatic variability during droughts, but partitioning shifts imply a change in the Budyko parameter $\omega$ and are related to less predictable nonlinear basin feedback mechanisms. We show that regime shifts dominate changes in absolute runoff during droughts, but that gains or losses due to partitioning shifts are still significant. Changes in absolute ET are influenced by both types of shifts.

Finally, we examine the correlation between partitioning shifts and known basin response mechanisms. We find that a low aridity index, high baseflow, shift from from snow to rain, and the resilience of high-elevation runoff correlate to increased runoff as a fraction of precipitation during droughts. These findings help characterize how different basins will respond to drought conditions, with implications for natural and human systems in drought-prone regions.

Data availability. The data sets generated for this study are available on request to the corresponding author.

Author contributions. TM contributed to the study design, data processing, modeling approach, and drafted the manuscript. FA contributed to the modeling approach and manuscript revisions. SG and RB contributed to manuscript revisions. All authors contributed to the article and approved the submitted version.

405 Competing interests. The authors declare that they have no conflict of interest.

Acknowledgements. We would like to thank Qin Ma for assistance with the evapotranspiration dataset. 
https://doi.org/10.5194/hess-2021-55

Hydrology and

Preprint. Discussion started: 29 March 2021

(c) Author(s) 2021. CC BY 4.0 License.

\section{References}

Avanzi, F., Rungee, J., Maurer, T., Bales, R., Ma, Q., Glaser, S., and Conklin, M.: Climate elasticity of evapotranspiration shifts the water balance of Mediterranean climates during multi-year droughts, Hydrology and Earth System Sciences Earth Science Systems, 24, 43174337, https://doi.org/10.5194/hess-24-4317-2020, 2020.

Bales, R. C., Goulden, M. L., Hunsaker, C. T., Conklin, M. H., Hartsough, P. C., O’Geen, A. T., Hopmans, J. W., and Safeeq, M.: Mechanisms controlling the impact of multi-year drought on mountain hydrology, Scientific Reports, 8, 1-8, https://doi.org/10.1038/s41598-01719007-0, 2018.

Berghuijs, W. R., Woods, R. A., and Hrachowitz, M.: A precipitation shift from snow towards rain leads to a decrease in streamflow, Nature Climate Change, 4, 583-586, https://doi.org/10.1038/nclimate2246, 2014.

Budyko, M.: Climate and Life, Academic Press, Inc., 1974.

Dai, A.: Increasing drought under global warming in observations and models, Nature Climate Change, 3, 52-58, https://doi.org/10.1038/nclimate1633, 2013.

Daly, C., Halbleib, M., Smith, J. I., Gibson, W. P., Doggett, M. K., Taylor, G. H., Curtis, J., and Pasteris, P. P.: Physiographically sensitive mapping of climatological temperature and precipitation across the conterminous United States, International Journal of Climatology, March, https://doi.org/10.1002/joc.1688, 2008.

Du, C., Sun, F., Yu, J., Liu, X., and Chen, Y.: New interpretation of the role of water balance in an extended Budyko hypothesis in arid regions, Hydrology and Earth System Sciences, 20, 393-409, https://doi.org/10.5194/hess-20-393-2016, 2016.

EROS Data Center: National Elevatoin Dataset, https://www.usgs.gov/core-science-systems/national-geospatial-program/national-map, 1999.

Fu, B.: On the Calculation of the Evaporation from Land Surface, Chinese Journal of Atmospheric Sciences, 5, 1981.

Gnann, S. J., Woods, R. A., and Howden, N. J.: Is There a Baseflow Budyko Curve?, Water Resources Research, 55, 2838-2855, https://doi.org/10.1029/2018WR024464, 2019.

Goulden, M. L. and Bales, R. C.: California forest die-off linked to multi-year deep soil drying in 2012-2015 drought, Nature Geoscience, 12, 632-637, https://doi.org/10.1038/s41561-019-0388-5, 2019.

Greve, P., Gudmundsson, L., Orlowsky, B., and Seneviratne, S. I.: A two-parameter Budyko function to represent conditions under which evapotranspiration exceeds precipitation, Hydrology and Earth System Sciences, 20, 2195-2205, https://doi.org/10.5194/hess-20-21952016, 2016.

Hahm, W. J., Dralle, D. N., Rempe, D. M., Bryk, A. B., Thompson, S. E., Dawson, T. E., and Dietrich, W. E.: Low Subsurface Water Storage Capacity Relative to Annual Rainfall Decouples Mediterranean Plant Productivity and Water Use From Rainfall Variability, Geophysical Research Letters, https://doi.org/10.1029/2019GL083294, 2019a.

Hahm, W. J., Rempe, D. M., Dralle, D. N., Dawson, T. E., Lovill, S. M., Bryk, A. B., Bish, D. L., Schieber, J., and Dietrich, W. E.: Lithologically Controlled Subsurface Critical Zone Thickness and Water Storage Capacity Determine Regional Plant Community Composition, Water Resources Research, 55, 3028-3055, https://doi.org/10.1029/2018WR023760, 2019b.

440 Hamon, W.: Computation of direct runoff amounts from storm rainfall, International Association of Hydrological Sciences Publication, 63, 52-62, 1963.

He, M., Russo, M., and Anderson, M.: Hydroclimatic characteristics of the 2012-2015 California drought from an operational perspective, Climate, 5, 1987-1992, https://doi.org/10.3390/cli5010005, 2017. 
Hofste, R. W., Reig, P., and Schleifer, L.: 17 Countries, Home to One-Quarter of the World's Population, Face Extremely High Water Stress, Tech. rep., World Resources Institute, Washington, D.C., https://www.wri.org/blog/2019/08/ 17-countries-home-one-quarter-world-population-face-extremely-high-water-stress, 2019.

Hrachowitz, M. and Clark, M. P.: The complementary merits of competing modelling philosophies in hydrology, Hydrology and Earth System Sciences, 21, 3953-3973, https://doi.org/10.5194/hess-21-3953-2017, 2017.

Huang, S., Li, P., Huang, Q., Leng, G., Hou, B., and Ma, L.: The propagation from meteorological to hydrological drought and its potential influence factors, Journal of Hydrology, https://doi.org/10.1016/j.jhydrol.2017.01.041, 2017.

Jaramillo, F., Cory, N., Arheimer, B., Laudon, H., Van Der Velde, Y., Hasper, T. B., Teutschbein, C., and Uddling, J.: Dominant effect of increasing forest biomass on evapotranspiration: Interpretations of movement in Budyko space, Hydrology and Earth System Sciences, 22, 567-580, https://doi.org/10.5194/hess-22-567-2018, 2018.

Klos, P. Z., Goulden, M. L., Riebe, C. S., Tague, C. L., O’Geen, A. T., Flinchum, B. A., Safeeq, M., Conklin, M. H., Hart, S. C., Berhe, A. A., Hartsough, P. C., Holbrook, W. S., and Bales, R. C.: Subsurface plant-accessible water in mountain ecosystems with a Mediterranean climate, Wiley Interdisciplinary Reviews: Water, 5, e1277, https://doi.org/10.1002/wat2.1277, 2018.

Li, D., Pan, M., Cong, Z., Zhang, L., and Wood, E.: Vegetation control on water and energy balance within the Budyko framework, Water Resources Research, 49, 969-976, https://doi.org/10.1002/wrcr.20107, 2013.

Li, Y., Liu, C., Yu, W., Tian, D., and Bai, P.: Response of streamflow to environmental changes: A Budyko-type analysis based on 144 river basins over China, Science of the Total Environment, 664, 824-833, https://doi.org/10.1016/j.scitotenv.2019.02.011, 2019.

Liu, J., Zhang, Q., Singh, V. P., and Shi, P.: Contribution of multiple climatic variables and human activities to streamflow changes across China, Journal of Hydrology, 545, 145-162, https://doi.org/10.1016/j.jhydrol.2016.12.016, 2017.

Masih, I., Maskey, S., Mussá, F. E., and Trambauer, P.: A review of droughts on the African continent: A geospatial and long-term perspective, Hydrology and Earth System Sciences, 18, 3635-3649, https://doi.org/10.5194/hess-18-3635-2014, 2014.

Maskey, S. and Trambauer, P.: Hydrological Modeling for Drought Assessment, Elsevier Inc., Delft, The Netherlands, https://doi.org/10.1016/B978-0-12-394846-5.00010-2, 2015.

Mastrotheodoros, T., Pappas, C., Molnar, P., Burlando, P., Manoli, G., Parajka, J., Rigon, R., Szeles, B., Bottazzi, M., Hadjidoukas, P., and Fatichi, S.: More green and less blue water in the Alps during warmer summers, Nature Climate Change, 10, 155-161, https://doi.org/10.1038/s41558-019-0676-5, 2020.

McVicar, T. R., Roderick, M. L., Donohue, R. J., and Van Niel, T. G.: Less bluster ahead? ecohydrological implications of global trends of terrestrial near-surface wind speeds, Ecohydrology, 5, 381-388, https://doi.org/10.1002/eco.1298, 2012.

Moussa, R. and Lhomme, J. P.: The Budyko functions under non-steady-state conditions, Hydrology and Earth System Sciences, 20, 48674879, https://doi.org/10.5194/hess-20-4867-2016, 2016.

Ning, T., Li, Z., and Liu, W.: Vegetation dynamics and climate seasonality jointly control the interannual catchment water balance in the Loess Plateau under the Budyko framework, Hydrology and Earth System Sciences, 21, 1515-1526, https://doi.org/10.5194/hess-21-1515-2017, 2017.

Ning, T., Zhou, S., Chang, F., Shen, H., Li, Z., and Liu, W.: Interaction of vegetation, climate and topography on evapotranspiration modelling at different time scales within the Budyko framework, Agricultural and Forest Meteorology, 275, 59-68, https://doi.org/10.1016/j.agrformet.2019.05.001, 2019.

480 Ning, T., Li, Z., Feng, Q., Chen, W., and Li, Z.: Effects of forest cover change on catchment evapotranspiration variation in China, Hydrological Processes, 34, 2219-2228, https://doi.org/10.1002/hyp.13719, 2020. 
https://doi.org/10.5194/hess-2021-55

Hydrology and

Preprint. Discussion started: 29 March 2021

(c) Author(s) 2021. CC BY 4.0 License.

O'Grady, A. P., Carter, J. L., and Bruce, J.: Can we predict groundwater discharge from terrestrial ecosystems using existing eco-hydrological concepts?, Hydrology and Earth System Sciences, 15, 3731-3739, https://doi.org/10.5194/hess-15-3731-2011, 2011.

Oroza, C. A., Bales, R. C., Stacy, E. M., Zheng, Z., and Glaser, S. D.: Long-Term Variability of Soil Moisture in the Southern Sierra: Measurement and Prediction, Vadose Zone Journal, 17, 170 178, https://doi.org/10.2136/vzj2017.10.0178, 2018.

Oudin, L., Andréassian, V., Lerat, J., and Michel, C.: Has land cover a significant impact on mean annual streamflow? An international assessment using 1508 catchments, Journal of Hydrology, 357, 303-316, https://doi.org/10.1016/j.jhydrol.2008.05.021, 2008.

Petheram, C., Potter, N., Vaze, J., Chiew, F., and Zhang, L.: Towards better understanding of changes in rainfall-runoff relationships during the recent drought in south-eastern Australia, in: MODSIM 2011 - 19th International Congress on Modelling and Simulation - Sustaining Our Future: Understanding and Living with Uncertainty, December, pp. 3622-3628, 2011.

Potter, N. J., Petheram, C., and Zhang, L.: Sensitivity of streamflow to rainfall and temperature in south-eastern Australia during the Millennium drought, in: MODSIM 2011 - 19th International Congress on Modelling and Simulation - Sustaining Our Future: Understanding and Living with Uncertainty, November 2014, pp. 3636-3642, 2011.

Roche, J. W., Ma, Q., Rungee, J., and Bales, R. C.: Evapotranspiration mapping for forest management in California's Sierra Nevada, Frontiers for Global Change, https://doi.org/10.3389/ffgc.2020.00069, 2020.

Roderick, M. L. and Farquhar, G. D.: A simple framework for relating variations in runoff to variations in climatic conditions and catchment properties, Water Resources Research, 47, 1-11, https://doi.org/10.1029/2010WR009826, 2011.

Rungee, J., Bales, R., and Goulden, M.: Evapotranspiration response to multiyear dry periods in the semiarid western United States, Hydrological Processes, 33, 182-194, https://doi.org/10.1002/hyp.13322, 2019.

500 Saft, M., Western, A. W., Zhang, L., Peel, M. C., and Potter, N. J.: The influence of multiyear drought on the annual rainfall-runoff relationship: An Australian perspective, Water Resources Research, 51, 2444-2463, https://doi.org/:10.1002/ 2014WR015348, 2016.

Shao, Q., Traylen, A., and Zhang, L.: Nonparametric method for estimating the effects of climatic and catchment characteristics on mean annual evapotranspiration, Water Resources Research, 48, 1-13, https://doi.org/10.1029/2010WR009610, 2012.

Shen, Q., Cong, Z., and Lei, H.: Evaluating the impact of climate and underlying surface change on runoff within the Budyko framework: A study across 224 catchments in China, Journal of Hydrology, 554, 251-262, https://doi.org/10.1016/j.jhydrol.2017.09.023, 2017.

Tague, C. and Grant, G. E.: Groundwater dynamics mediate low-flow response to global warming in snow-dominated alpine regions, Water Resources Research, 45, 1-12, https://doi.org/10.1029/2008WR007179, 2009.

Teuling, A. J., Van Loon, A. F., Seneviratne, S. I., Lehner, I., Aubinet, M., Heinesch, B., Bernhofer, C., Grünwald, T., Prasse, H., and Spank, U.: Evapotranspiration amplifies European summer drought, Geophysical Research Letters, 40, 2071-2075, https://doi.org/10.1002/grl.50495, 2013.

Thomas, H. A.: Improved methods for national water assessment, water resources contract: WR15249270, Tech. rep., U.S. Geological Survey, https://doi.org/10.3133/70046351, 1981.

Tian, W., Bai, P., Wang, K., Liang, K., and Liu, C.: Simulating the change of precipitation-runoff relationship during drought years in the eastern monsoon region of China, Science of the Total Environment, 723, 138 172, https://doi.org/10.1016/j.scitotenv.2020.138172, 2020.

515 Trenberth, K. E., Dai, A., van der Schrier, G., Jones, P. D., Barichivich, J., Briffa, K. R., and Sheffield, J.: Global warming and changes in drought, Nature Climate Change, 4, 17-22, https://doi.org/10.1038/nclimate2067, 2014.

Troch, P. A., Lahmers, T., Meira, A., Mukherjee, R., Pedersen, J. W., Roy, T., and Valdés-Pineda, R.: Catchment coevolution: A useful framework for improving predictions of hydrological change?, Water Resources Research, 51, 4903-4922, https://doi.org/10.1002/2015WR017032, 2015. 
https://doi.org/10.5194/hess-2021-55

Preprint. Discussion started: 29 March 2021

(c) Author(s) 2021. CC BY 4.0 License.

(c) (1)

Van Loon, A. F.: Hydrological drought explained, Wiley Interdisciplinary Reviews: Water, 2, 359-392, https://doi.org/10.1002/wat2.1085, 2015.

Wang, D. and Alimohammadi, N.: Responses of annual runoff, evaporation, and storage change to climate variability at the watershed scale, Water Resources Research, 48, https://doi.org/10.1029/2011WR011444, 2012.

Wang, D. and Tang, Y.: A one-parameter Budyko model for water balance captures emergent behavior in darwinian hydrologic models, Geophysical Research Letters, 41, 4569-4577, https://doi.org/10.1002/2014GL060509, 2014.

Woodhouse, C. A., Meko, D. M., MacDonald, G. M., Stahle, D. W., and Cook, E. R.: A 1,200-year perspective of 21st century drought in southwestern North America, Proceedings of the National Academy of Sciences of the United States of America, 107, 21 283-21 288, https://doi.org/10.1073/pnas.0911197107, 2010.

Yang, D., Sun, F., Liu, Z., Cong, Z., Ni, G., and Lei, Z.: Analyzing spatial and temporal variability of annual water-energy balance in nonhumid regions of China using the Budyko hypothesis, Water Resources Research, 43, 1-12, https://doi.org/10.1029/2006WR005224, 2007.

Yang, D., Shao, W., Yeh, P. J., Yang, H., Kanae, S., and Oki, T.: Impact of vegetation coverage on regional water balance in the nonhumid regions of China, Water Resources Research, 45, 1-13, https://doi.org/10.1029/2008WR006948, 2009.

Zhang, L., Dawes, W. R., and Walker, G. R.: Response of mean annual evapotranspiration to vegetation changes at catchment scale, Water Resources Research, 37, 701-708, https://doi.org/10.1029/2000WR900325, 2001.

Zhang, L., Hickel, K., Dawes, W. R., Chiew, F. H., Western, A. W., and Briggs, P. R.: A rational function approach for estimating mean annual evapotranspiration, Water Resources Research, 40, 1-14, https://doi.org/10.1029/2003WR002710, 2004.

Zhang, L., Potter, N., Hickel, K., Zhang, Y., and Shao, Q.: Water balance modeling over variable time scales based on the Budyko framework - Model development and testing, Journal of Hydrology, 360, 117-131, https://doi.org/10.1016/j.jhydrol.2008.07.021, 2008.

540 Zhang, S., Yang, H., Yang, D., and Jayawardena, A. W.: Quantifying the effect of vegetation change on the regional water balance within the Budyko framework, Geophysical Research Letters, 43, 1140-1148, https://doi.org/10.1002/2015GL066952, 2016.

Zhang, Z., Glaser, S., Bales, R., Conklin, M., Rice, R., and Marks, D.: Insights into mountain precipitation and snowpack from a basin-scale wireless-sensor network, Water Resources Research, 53, 6626-6641, https://doi.org/10.1002/2016WR018825, 2017. 